\title{
IDENTIDADES CONTEMPORÁNEAS: Ser a través de la historia y de la palabra
}

\section{C ontemporary identities: Being throughout the history and the speech}

\begin{abstract}
Adolfo Pizzinato
D octor en Psicología de la Educación por la Universitat A utònoma de Barcelona (UAB) - Becario CAPES, Profesordel curso de Psicología de la Universidade Luterana do Brasil (ULBRA/Canoas), Porto Alegre, RS - Brasil, e-mail: adolfopizzinato@yahoo.com.br
\end{abstract}

\section{Resumen}

El presente artículo se propone a discutir el concepto de identidad, bajo la influencia de aspectos claves para la definición de este concepto: la narratividad y la contemporaneidad, en una perspectiva psicosocial. La primera, parte de los orígenes histórico culturales de este concepto en psicología, hasta las aportaciones de la lingüística. La segunda se refiere al proyecto identitário de la modernidad, ahora re-significado por cuestiones tan centrales como la globalización.

Palabras-clave: Identidad; Narratividad; Contemporaneidad.

\begin{abstract}
This article intends to discuss the concept of identity, under the influence of key aspects for the definition of this concept: the narrativity and the contemporaneity, on a psychosocial perspective. The first, leaves from the historic cultural origins of the concept in psychology, until the contributions of linguistics. The second, relates to the identitarian project of modernity, now resignificated by central issues as the globalization.
\end{abstract}

Keywords: Identity; Narrativity; Contemporaneity. 


\section{INTRODUCCIÓN}

\section{Identidad: N arrativa, cultura y sociedad}

De manera consonante con el "giro" lingǘstico vivido por las ciencias sociales en la contemporaneidad, se puede entender las instituciones como un espacio discursivo constituido a través de las prácticas de lenguaje y en particular en el contar y re-contar "historias". Las identidades desarrolladas en estos entornos discursivos son múltiples y pueden ser complementarias, competentes, contradictorias, distintas o próximas, hegemónicas o no, pero es en la confluencia de muchas de las narrativas identitárias individuales quese construyeunaidentidad colectiva compartida, como puede ser la de una escuela o comunidad (Brown, Humphreys \& G urney, 2005).

Las narrativas pueden ser entendidas como relatos cargados de valor simbólico, de maneras activas e involucradas por palabras que incorporan secuencia, tiempo y lugar, constitutivas de las identidades sociales y personales. El énfasis se debe poner en la acción social donde sucede, 0 en la naturaleza de la construcción de las descripciones y relatos, que hacen las personas cuando utilizan recursos particulares en los relatos (Verkuyten \& de Wolf, 2002).

Las identidades individuales y colectivas tienen su autoría dentro de un régimen discursivo que proviene delos actores sociales con importantes recursos simbólicos por la negociación de la identidad. Estos recursos pueden ser posiciones 0 espacios a ocupar. Las identidades narrativas no son estáticas y no se completan nunca. Están en constante proceso de ser "complementadas", asimiladas, mezcladas, refinadas, elaboradas y sumergidas en "un todo" de historias que se regulan y se construyen unas a las otras (Verkuyten \& de Wolf, 2002). Laidea que las identidades individuales son subjetivamente evaluables a través de las narraciones de las experiencias que comunican, tiene un sentido de unicidad biográfica, y es ahora muy consolidada (Verkuyten \& de Wolf, 2002). Según la idea de Bruner (1997), las personas se vuelven quién son a través de contar historias sobre sus vidas y vivir las historias que cuentan en los espacios territoriales y temporales en que viven. Estos espacios, o marcadores, pueden ser entendidos como puntos clave para el entendimiento de la identidad contemporánea, tanto en su dimensión psicológica más narrativa, como en su dimensión psicosocial e histórica.

Conforme apunta Santos (2001), la intensificación de la interdependencia transnacional y de las interacciones globales haz con que las relaciones sociales parezcan hoy cada vez más desterritorializadas, ultrapasando las fronteras de los costumbres, delosnacionalismos, delosidiomas, de las ideologías y de todos los demás "marcadores" de frontera antropológica validos desde el siglo XIX y hasta bien recientemente (Pizzinato, 2003). Entretanto, en este contexto emergen otras características de la post-modernidad: la ambivalencia, la dualidad, la contradicción.

Cuestiones que parecían obvias, como las propias nacionalidades, por ejemplo, actualmente pueden cobrar sentidos bastantes más subjetivos que en las perspectivas "clásicas", que simplemente eran limitadas por el sitio denacimiento. Laidentidad nacional, por ejemplo, puede ser entendida como un espacio psicosocial de pertenecer, que supone algunos trazos significativos y una conciencia más o menos elaborada de compartir un espacio vital. El reconocimiento de una identidad nacional implica la adquisición de creencias, actitudes y valores socialmente compartidos dentro de un grupo y posibles de evaluación, tanto dentro como fuera do grupo, a través de la comparación social (Matera, Giannini, Blanco \& Smith, 2005).

Al mismo tiempo, se asiste al surgimiento o re-significación de identidades regionales y locales basadas en una revitalización del derecho a las "raíces" (en contrapunto al derecho a la elección). Esta referencia tan local, que podría otrora ser categorizada como premoderna, y hoy es renombrada post-moderna, presentase más intensa entre personas y grupos "transubicados" (Santos, 2001). Estas personas, en mayoría, inmigrantes y/ o sus descendientes, están conectadas por un sentido de lugar específico, de territorio, sea él imaginario 0 simbólico, real o hiper-real (Pizzinato, 2003).

Esta referenciación de identidad aun es más explícita se consideramos una de las principales facetas de la post-modernidad: la globalización. La globalización existe desde hace muchos siglos (sobretodo después de la Revolución Comercial de finales del siglo XV) como proceso por el cual culturas se han influenciado y se han tornado más próximas a través del comercio, de la inmigración y del intercambio de informaciones e ideas (Santos, 2001). Entretanto, en décadas más recientes, el 
grado y la intensidad de conexiones entre distintas culturasy diferentes regiones globales sehaacelerado dramáticamente, debido a los avances en telecomunicaciones y al rápido incremento de interdependencias financieras y económicas a través del mundo (Pizzinato, 2003). Consecuentemente, en años recientes, la globalización se ha tornado uno de los términos más ampliamente empleados para describir el actual estado mundial (Arnett, 2002). Evidentemente, la globalización también se refleja en los procesos narrativos de construcción social de las identidades, una vez que las pautas discursivas, los género literarios, los modelos culturales y los roles sociales pasan por el mismo proceso de "comunión" global, sobretodo si consideramos la industria cinematográfica y la televisión (todo y que ambas no sean un ejemplo de democracia en este proceso de compartir referenciales), muy marcadas por los ideales de la cultural occidental euro-orientada, impuestos como los referenciales del mundo globalizado, que niega, a la vez que venera, las fronteras culturales (Pizzinato, 2007; Pizzinato \& Sarriera, en prensa).

Actualmente, la obsesión por las fronteras de identidad se genera del deseo, consciente 0 inconsciente de buscar un sitio suficientemente confortable, acogedory seguro, en un mundo que se presenta salvaje, imprevisible y amenazante. Resistir a la corriente, protegerse de las fuerzas externas que parecen invencibles, y que no se pueden controlar ni detener. Sea cual sea la naturaleza de estas fuerzas, ella es identificada por el término mismo que la confunde: la globalización (Bauman, 2006).

Por el hecho de este concepto ser indiscriminadamente empleado, la contribución de la psicología para el entendimiento dela globalización es aun predominantemente indirecta. Aunque los efectos indirectos de la globalización, en lo que se refiere a la identidad, sean descriptos en investigaciones y teorías psicológicas, la globalización ejerce una influencia primaria en muchas cuestiones de la identidad en los días de hoy, sobretodo a través de la media global, que imprime un patrón narrativo que influencia todo el proceso evolutivo de la identidad, una vez que este es marcadamente contextual, cultural y simbólica (Pizzinato, 2003).

D entro de la perspectiva sociocultural - y en sus raíces - los trabajos de Vygotsky, Luria y Bahktin, ya proveían lapsicologíadeunaherramienta útil por considerar la función de la narrativa en el desarrollo humano dentro de un contexto cultural
(Davis, 2004). Vygotsky (1997a) demostró que el orden superior de la cognición humana es posible gracias a la internalización de las herramientas simbólicas. D eestas herramientas, la más importante es el lenguaje que, se desarrolla en los niños, primeramente como signos que representan objetos y acciones particulares y después se internalizan como símbolos, herramientas para resolver problemas e imaginar acciones futuras.

Como representaciones de experiencias complejas reducidas al lenguaje, al sonido y a las imágenes, las historias funcionan como herramientas simbólicas, formas de entender la experiencia como un despliegue en tiempo y espacio (Bruner, 1997). Bakhtin desarrolló una teoría "dialógica" que conectaba la experiencia de vida con la autoría, Bakhtin propuso que el lenguaje y los géneros se presentan a las personas a través de la participación cultural y se volvían las bases de significado por las cuales se interpretará y se responderá al mundo (Davis, 2004). Las respuestas que se dan a los mensajes de cada momento de la existencia son como un proceso autoral en primera persona. Cada persona es autora de su propia historia y como en cada acto autoral, la elección y la interpretación son imprescindibles. Pero también cada acto de autoría es un acto de co-autoria. Las palabras e interpretaciones disponibles por las personas originalmente no pertenecen a estas personas, pero sus historias están presente en la interacción con los otras y sus palabras y actos ubican los autores y las interpretaciones asertivas por las cuales responden los autores (D avis, 2004).

O chs y Capps (1996), en su revisión comprensiva de la literatura narrativa sobre el self (el yo) proveen una explicación adicional a la idea de que el self se inseparable de la narrativa. La narrativa es un recurso esencial en la lucha por traer las experiencias a la conciencia y es el significado por el cual se puede mediar la experiencia en el mundo. Las narrativas personales dan forma a como se ve y se siente ante diferentes situaciones. Son "cuentos", que narradores y audiencia cartografían en contar historias, experiencias personales. Y es más, el acto de la narración da forma al ser del self. O chs y Capps (1996) describen como narradores utilizan su propia narrativa en primera persona como herramienta simbólica para el auto-entendimiento. Exteriorizar sus historias a través de la elección de las palabras, grados de elaboración, atribuciones de causalidad y secuencialidad $\mathrm{y}$, las tiradas "adelante" y las 
referencias a las experiencias pasadas (back grounding) de emociones, circunstancias y conductas, los narradores construyen un entendimiento novelístico de ellos mismos en el mundo.

Este entendimiento novelístico del self sirve como herramientasimbólica por los narradores, en el sentido que se vuelven disponibles para mediar actividades futuras. La manera como una persona persigue su "fin", es mediado por como el autor entiende que debería ser en un despliegue cronológico de la experiencia (D avis, 2004). En este sentido, el aprendizaje puedeser transformador, así como adicional: se aprende de la experiencia cuando se internalizan representaciones simbólicas dibujadas por la propia experiencia, estas, alternadamente permiten transformaciones cualitativas en la forma de actuar de una por otra (Vygotsky, 1997b). La narrativa es un medio por el cual se aprende de la experiencia a través de la reflexión sobre esta, declarando qué significa y "destilando" este significado en una manera simbólica para ser expresada y recordada (D avis, 2004). Este proceso es esencialmente flexible, desplegándose en sí mismo: la experiencia es transformada en narrativa y la narrativa en sí misma se transforma en una herramienta que da forma a la memoria y a las experiencias futuras inmediatas.

Pero como la autoría se da en lainteracción con los demás - "otros" estos que incluso pueden confirmar quien es el autor y nutridlo de interpretaciones, o incluso ser sólo "simbólicos" esto deriva en un aspecto político, un aspecto que rodea el habilitado en ponerse y de dar forma al contar su propia historia. Pero, ¿quien puede explicar una historia? ¿Cómo los demás la interpretan 0 responden? ¿Q uépartes delahistoria son silenciadas por las ideologías dominantes? Estas son las preguntas que formula D avis (2004), y pertenecen a la construcción de la identidad en las múltiples palabras en que el autor actúa y también en el contexto directo de la autoría.

En el campo de la psicología, nociones como las de self, identidad y subjetividad remiten a modelos teóricos dirigidos a la totalidad de la persona, y no a comportamientos o funciones mentales aisladas. La visión del self más frecuente en la psicología, se remite a la tradición filosófica que va desde D escartes hasta Kant y Piaget: el self como el si mismo, la toma de conciencia de que "se es" una entidad independiente y autónoma del otro (Lopes de Oliveira, 2006). Pese a que presenta perfecta consonancia con el encuadre racionalista del psiquismo, esta noción de self expresa una concepción individualista y auto-contenida de la unidad psíquica, incongruente con las perspectivas defendidas por Lopes de Oliveira (2006) y por Nelson (2000). La identidad subjetiva se reorganiza interna y externamente con la relación con el otro y con la cultura (Rey, 2003). El contexto cultural tiene el rol de regular las condiciones sociales de constitución del sentido de si mismo. Las prácticas socioculturales median la formación de la autoimagen y de las significaciones sobre sí. Se destacan la centralidad de las narrativas como instrumento de organización auto-epistémica de la experiencia subjetiva y social, y consecuentemente, de la vida mental (Bamberg, 2004; Bruner, 1997).

La integración dinámica de estos aspectos resulta en una subjetividad de naturaleza plural y polifónica(Hermans 2001; Lopes de O liveira, 2006), que se contrapone a la perspectiva de un self individualizado y auto-contenido. Como resultado, lo que se defiende es una visión crítica de las perspectivas metafísicas sobre la subjetividad y del self, declarando la adhesión a una comprensión de la unidad psíquica interdependiente en relación al "otro", tanto como de las interacciones sociales sucedidas en contextos socio institucionales concretos, y teniendo como principal medio de organización el lenguaje humano en acto (Lopes de Oliveira, 2006). Según Valsiner (1995), el self puede ser entendido como el sistema integrado de la cultura personal construida según las sugerencias sociales que inciden sobre su estilo idiosincrásico. La cultura personal incluye la unidad de afecto y racionalidad. En el self, toda idea racional tiene su contexto afectivo y todo sentimiento está intrínsecamente atado a alguna forma de pensamiento sobre la persona o sobre el mundo.

Los estudios que buscaban aliar la comprensión de la subjetividad en la formación del análisis narrativo, comparten la visión de que el lenguaje tiene un papel central como l'expresión de la identidad y como constitutiva de l'experiencia humana en el mundo. El sin'd identidad s'expresa en la formación de historias - vividas, contadas, recontadas y intersubjectivamente transformadas. Este carácter "historiado" de la identidad permitiría referirse a ella como identidad narrativa. Las historias contadas por una persona son simultáneamente una prácticasocial (dirigidas aunaaudiencia, estructuradas con base en una lengua por la cual la persona vuelve 
pública la experiencia privada, y cuentan creencias, valores e ideologías proviniendo del contexto sociocultural), y una actividad auto-epistémica (Wortham, 2000), por medio de la cual la persona se reconoce y se transforma, en el engendrar de nuevos significados y comportamientos y al tomar posición ante ellos, dentro de una perspectiva ética.

De esta forma, el abordaje de las prácticas narrativas explora su dimensión de creación de la novedad, el narrar como acto d'emergencia, por oposición al lenguaje como ventana por la mente y la narración como acto de revelación d'una subjetividad preexistente (Lopes de O liveira, 2006). De la manera como se entiende aquí, las narrativas constituyen el contexto micro genético en que las personas se presentan públicamente y se constituyen, contra el telón defondo dado porel contexto socio institucional en que se insere la interacción, un sentido de sí sustentado ínter subjetivamente (Korobov \& Bamberg, 2004). En el contexto de las interacciones discursivas, las personas desarrollan estrategias retóricas que darán el apoyo necesario para la constitución de un sentido de sí, al mismo tiempo imaginario (sostenido en imágenes sociales y personales) y discursivo. Estas estrategias buscan, todavía, garantizar que el otro social, en el contexto ínter subjetivo, interprete cada cual de forma coherentecon su proyecto subjetivo (Bamberg, 2004).

Como escenario del sentido de si, las narrativas son el contexto del cruce de temporalidades, y en permanente tensión entre la ilusión de continuidad y la coherencia temporal y el tiempo vivido; experiencial, cíclico, ilógico: de un lado, la ilusión de continuidad (identidad) preservando la noción de que se "es" una misma persona, a pesar de los profundos cambios que cada uno pasa en el ciclo del desarrollo; de otra manera, el paso del tiempo (desarrollo) como la propia condición de inteligibilidad de la narrativa (Lopes de Oliveira, 2006). Laidentidad puede ser entendida como un constructo conceptual que combinan las dimensiones de "insideness", visto como personal, y de "outsideness", entendido como los factores sociales, históricos y culturales. Esta noción, que plantean Lacasa, del Castillo y G arcía-Varela (2005), como bien reconocen ellos mismos, no es una noción nueva, puesto que autores como Mead (1967, en Lacasa, del Castillo \& García-Varela, 2005) ya en los años 1930, distinguía entre "I" y "me" (o entre el yo y el mí). El "yo" sería la respuesta del organismo verso las actitudes de los otras y el "mí" sería el sistema organizado d'actitudes de los otras que uno asume por si mismo.

En el proceso de descubrir como la identidad es generada por la combinación de la persona, cultura y práctica y el rol que las instituciones producen puede ser particularmente interesante, cuando involucran dos propiedades mayores (Lacasa, del Castillo \& García-Varela, 2005). La primera es su estructura y organización, en contextos específicos, como por ejemplo las escuelas; las personas organizan sus relaciones de acuerdo con los roles y normas que obligan las acciones de cada individuo. La segunda son las instituciones, que pueden estar relacionadas con las obligaciones que tienen como actores de sedes propios grupos, y esto se produce en el contexto en que se generan conceptos y valores que guían las prácticas sociales (Lacasa, del Castillo \& GarcíaVarela, 2005). Porlo tanto, yen estamismadirección, la presente revisión pretendecomprender la relación entre los aspectos narrativos de la construcción de la identidad, considerando los aspectos culturales, socio cognitivos, lingǘsticos e institucionales que interactúan en la formación de la conciencia del self, en una propuesta que considera la interfaz de la psicología con el tiempo, el espacio y el contexto de producción de significados compartidos.

\section{CON SIDE RACIONES FINALES}

Si se consideran los argumentos presentados, como elementos presentes y constituyentes de los procesos de construcción de la identidad, se puede concluir que el lenguaje no se entiende mejor como un espejo que refleja un mundo objetual independiente (la antigua definición de realidad), sino como un recurso que presta forma a nosotros mismosy a nuestro mundo a partir del flujo contingente y desordenado de la práctica cotidiana. El lenguaje y el discurso no representan a los objetos ni a la realidad, sino que, más bien los constituyen, haciéndolos existir, de manera que hay que concebir las relaciones sociales están discursivamente constituidos en y mediante el lenguaje, más bien que representados por éste (Baker, 2003).

Teniendo en cuenta, tanto la dimensión narrativa (o discursiva), como la dimensión sociocultural, se puede concluir que las identidades son construcciones discursivas, es decir, descripciones de nosotros mismos con las que nos identificamos y 
en las que nos volcamos emocionalmente. También la identidad conlleva una dimensión social y cultural, "de principio a fin", por lo que se entiende que son construcciones completamente sociales y contextuales, no existiendo fuera de las representacionesculturales. No seposeunaidentidad, sino que se es más bien un yo fracturado, producto de un complejo entramado de actitudes y creencias.

\section{REFERENCIAS}

Arnett, J. J. (2002). The psychology of globalization. American Psychologist, 57(10), 774-783.

Barker, C. (2003). Televisión, globalización e identidades culturales. Barcelona: Paidós.

Bamberg, M. (2004). Form and functions of "Slut-Bashing" in male identity constructions in 15-years-olds. H uman Development, 249, 331-353.

Bauman, Z. (2006). Confianza y temor en la ciudad: Vivir con extranjeros. Barcelona: A rcadia.

Brown, A., Humphreys, M., \& Gurney, P. M. (2005). Narrative, identity and change: a case study of Laskarina Holidays. Journal of Organizational Change Management, 18(4), 312-326.

Bruner, J. (1997). La educación, puerta de la cultura. Madrid: Visor.

D avis, A. (2004). Co-authoring identity: Digital storytelling in an urban middle school. Then - Technology, humanities, education and narrative. Recuperado en 12 oct 2007, da Then (Technology, humanities, education and narrative On line): www. thenjournal.org/ feature/ 61/

Hermans, J. M. (2001). The dialogical self: Toward a theory of personal and cultural positioning. Culture \& Psychology, 7(3), 243-282.
Korobov, N., \& Bamberg, M. (2004). Positioning a "mature" self in interactive practices. How adolescent males negociate 'physical attraction' in a group talk. British Journal of Developmental Psychology, 22, 471-492.

Lacasa, P., del Castillo, H., \& García-Varela, A. B. (2005). A bakhtinian approach to identity in the context of institutional practices. Culture \& Psychology, 11, (3), 287-308.

Lopes de Oliveira, M. C. S. (2006). Identidade, narrativa e desenvolvimento na adolescência: uma revisão crítica. Psicologia em E studo, 11(2), 427-436.

Matera, C., Giannini, M., Blanco, A., \& Smith, P. B. (2005). Autoestereotyping and nacional identity in the spanish context. Interamerican Journal of Psychology, 39(1), 83-92.

Nelson, K. (2000). Narrative, time and the emergence of the encultured self. Culture \& Psychology, 6(2), 209-223.

O chs, E., \& Capps, L. (1996). Narrating the self. American Review of Anthopology, 25, 19-43.

Pizzinato, A. (2003). Identificar(se) na pósmodernidade: etnicidade e globalização. En: P. Guareschi, A. Pizzinato, M. K. Macedo \& L. Krüger (Eds.). Psicologia em Questão: Reflexões sobre a Contemporaneidade. (pp. 1532). Porto Alegre: Edipucrs.

Pizzinato, A. (2007). Cultura, identitat i narrativa: L'aprenentatge col-laboratiu a l'escola intercultural. Tesis doctoral no publicada. Bellaterra: Universitat Autònoma de Barcelona.

Pizzinato, A., \& Sarriera, J. C. (en prensa). Identidade: Elementos de etnicidade entre escolares no Brasil. Revista Interamericana de Psicologia, 42.

Rey, F. G. (2003). Sujeito e sujetividade: Uma aproximação histórico-cultural. São Paulo: Pioneira - Thompson Learning. 
Santos, B. de S. (2001). Pela mão de Alice: 0 social e o político na pós-modernidade. Rio de Janeiro: Cortez.

Valsiner, J. (1995). Editorial culture and psychology. Culture \& Psychology, 1, 5-10.

Verkuyten, M., \& de Wolf, A. (2002). Being, feeling and doing: discourses and ethnic selfdefinitions among minority grup members. Culture \& Psychology, 8(4), 371-399.

Vygotsky, L. S. (1997a). Psicologia e educação. Martins Fontes: São Paulo.

Vygotsky, L. S. (1997b). Pensamento e linguagem. Martins Fontes: São Paulo.

Wortham, S. (2000). Interactional positioning and narrative self-construction. N arrative Inquiry, 10(1), 157-184.

Recebido: 14/ 05/ 2008

Received: 05/ 14/ 2008

Aprovado: 29/07/ 2008

A pproved: 07/ 29/ 2008 